\section{LA INFLUENCIA DE LA HISTORIA EN}

LA CONSTRUCCIÓN DEL PENSAMIENTO ENFERMERO

Híades. Revista de Historia de la Enfermería El Salvador: Imprenta Rilcadone. José Siles González

CEU Facultad Ciencias de la Salud. Universidad de Alicante Cómo citar este artículo (reseña) en edición digital: Siles González, J. (2015). Una nueva joya para la historia de la enfermería española: La influencia de la historia en la construcción del pensamiento enfermero (Híades). (Reseña). Cultura de los Cuidados (Edición digital) 19, 42. Disponible en: http://dx.doi.org/10.14198/cuid.2015.42.19> Correspondencia: (remitirse al correo electrónico)

Correo electrónico: jose.siles@ua.es. Recibido: 10/06/2015/ Aceptado: 22/06/2015

\section{Una nueva joya para la historia de la enferme- ría española}

Gracias a la labor ardua y constante de Antonio Claret García Martínez y su hermano Manuel Jesús García Martínez, nos felicitamos por encontrarnos de nuevo con el último (hasta la fecha) ejemplar de la única publicación monotemática de historia de la enfermería. Efectivamente, acaba de aparecer el número 11 de Híades, "Revista de Historia de la Enfermería”, el cual integra entre sus 896 páginas la mayor parte de las aportaciones que tuvieron lugar durante el XI Congreso Nacional y VI Internacional de Historia de la Enfermería, celebrado en Barcelona entre los días 25 y 27 de noviembre de 2010 :

"Bajo el título de La influencia de la Historia en la construcción del pensamiento enfermero este número monográfico de Híades incluye 82 trabajos que abordan un rico y variado espacio de investigación histórica y que muestran las amplias posibilidades de estudio de la Historia de la Enfermería en España y su proyección por el resto del mundo. El contenido científico queda

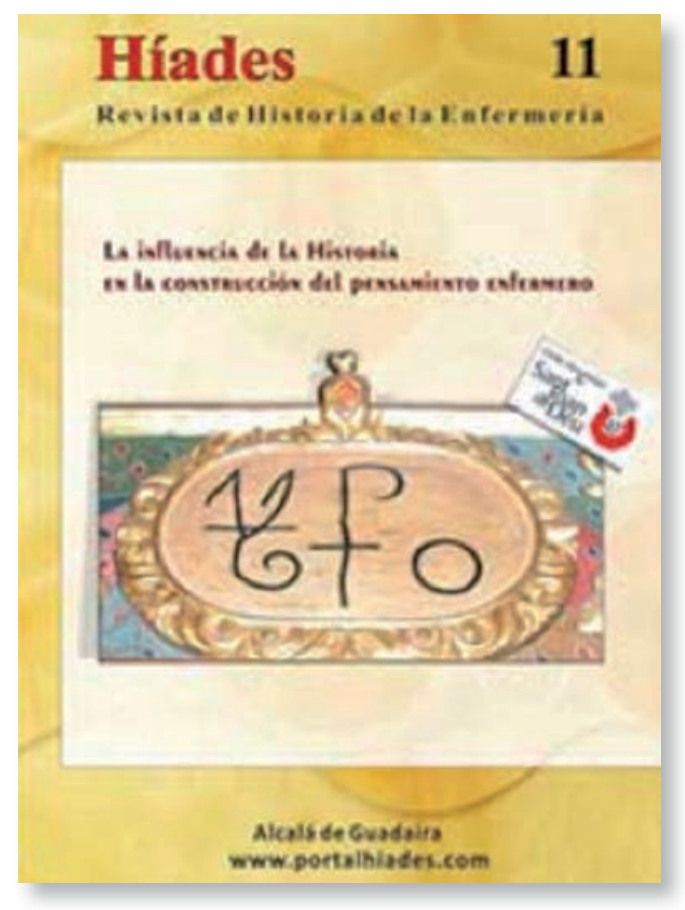

organizado en cuatro apartados temáticos y los pósteres:

1. Investigación en Historia de la Enfermería y la construcción disciplinar.

2. Precursores y líderes en la consolidación del pensamiento enfermero.

3. Las demandas sociales a lo largo de la Historia como motor de cambio de la praxis enfermera.

4. La Historia de la formación enfermera y su contribución en la profesión.

\section{Pósteres.}

6. Homenajes y Exposiciones. En conjunto, la investigación de la Historia de la Enfermería en España se ha convertido en uno de los pilares más sólidos de la investigación enfermera y nadie que esté interesado en la misma debe dejar de leer esta interesante compilación"

\section{Fuente: http://www.portalhiades.com/}

Sin duda, la historia de la enfermería española no sería la misma sin esta publicación ni la actividad incansable de los que la hacen posible. Nuestro agradecimiento y enhorabuena a sus directores y a todos sus colaboradores. 